\title{
KISS1 R signaling modulates gonadotropin sensitivity in mouse Leydig cell
}

\author{
Meng-Chieh Hsu®, Leang-Shin Wu, De-Shien Jong and Chih-Hsien Chiu \\ Department of Animal Science and Technology, National Taiwan University, Taipei, Taiwan \\ Correspondence should be addressed to C-H Chiu; Email: chiuchihhsien@ntu.edu.tw
}

\begin{abstract}
Kisspeptin and its receptor KISS1R have been proven as pivotal regulators on controlling the hypothalamus-pituitary-gonad axis. Inactivating mutations in one of them cause idiopathic hypogonadotropic hypogonadism in human as well as rodent models. Notably, gonadotropin insensitivity, failure in hCG response, was presented in the male patients with loss-function-mutations in KISS1R gene; this reveals the essential role of KISS1R signaling in regulating testosterone production beyond the hypothalamic functions of kisspeptin. In this study, we hypothesized that the autocrine action of kisspeptin on Leydig cells may modulate steroidogenesis. Based on the mouse cell model, we first demonstrated that the cAMP/protein kinase A (PKA)/cAMP response element-binding protein (CREB) signaling pathway mediated gonadotropin-induced kisspeptin expression. By using siRNA interfering technique, knockdown of Kiss1 $r$ in MA-10 cells, a mouse Leydig tumor cell line, significantly reduced progesterone productions in both basal and hCG-treated conditions. Integrating the results from both quantitative real-time PCR and steroidogenic enzyme-activity assay, we found that this steroidogenic defect was associated with decreased luteinizing hormone/choriogonadotropin receptor (Lhcgr) and StAR protein (Star) expressions. Furthermore, exogenous expression of human LHCGR completely rescued hCG-stimulated progesterone production in the KISS1R-deficient cells. In conclusion, we proposed that the reproductive functions of KISS1R signaling in Leydig cell include modulating $\mathbf{L h c g r}$ and steroidogenic gene expressions, which may shed the light on the pathophysiology of gonadotropin insensitivity. Reproduction (2020) $160843-852$
\end{abstract}

\section{Introduction}

In mammals, kisspeptin is thought to be an indispensable regulator for the activation of hypothalamus-pituitarygonad axis by stimulating the gonadotropin-releasing hormone $(\mathrm{GnRH})$ neuron, which expresses the kisspeptin receptor, KISS1R, also known as GPR54. Inactivating mutations in KISS1 or KISS1R cause idiopathic hypogonadotropic hypogonadism, a syndrome characterized by deficient production of $\mathrm{GnRH}$, gonadotropins and sex steroid hormones, leading to incomplete sexual maturation (Ohtaki et al. 2001, de Roux et al. 2003, Funes et al. 2003, Seminara et al. 2003, Messager et al. 2005). The human kisspeptin precursor contains 145 amino acids and can be proteolytically cleaved into peptides of different lengths, including kisspeptin-54, kisspeptin-14, kisspeptin-13 and kisspeptin-10. These peptides contain a common C-terminal decapeptide sequence and have similar biological activities triggering intracellular calcium mobilization (Kotani et al. 2001). Aside from the hypothalamus, several non-neuronal tissues express Kiss 1 , Kiss $1 r$ or both, and their local functions are continuously investigated nowadays (Ohtaki et al. 2001, Funes et al. 2003, Hussain et al. 2015, Chianese et al. 2018).
The previous study had demonstrated that Kiss 1 expression in mouse testis was correlated to postnatal testicular development (Wang et al. 2015). Further, luteinizing hormone (LH) is regarded as a stimulator to prompt kisspeptin production in the Leydig cell (Salehi et al. 2015). However, the intracellular signaling pathway in LH-induced Kiss 1 expression has not yet been well described. In the Leydig cell, the primarily downstream signal transduction pathway of luteinizing hormone/choriogonadotropin receptor (LHCGR) is the cyclic AMP (CAMP)/ protein kinase A (PKA) pathway (Hansson et al. 2000). Following the signaling cascade, a transcription factor CAMP-responsive element-binding protein (CREB), a target protein of PKA with the serine 133 phosphorylation, is activated and regulates several steroidogenic enzyme expressions, such as StAR protein (StAR) (Gonzalez \& Montminy 1989, Manna et al. 2002). In the view of LHCGR signaling cascade, we proposed that, in the mouse Leydig cells, CREB might mediate LH-induced Kiss 1 expression.

As both kisspeptin and KISS1 R exist in the mammalian testes, and Kiss 1 expression is correlated to testicular development (Salehi et al. 2015, Wang et al. 2015, Han et al. 2020), it raised a hypothesis that autocrine and paracrine actions of kisspeptin might be involved in 
regulating two major testicular functions, testosterone biosynthesis and spermatogenesis (Chianese et al. 2016, Wahab et al. 2016, Sharma et al. 2020). Indeed, several studies had examined the effect of kisspeptin on steroidogenesis. However, the conclusions contained some discrepancies. In the in vitro experiments, kisspeptin-10 did not directly increase steroid hormone production or synergize with the hCG stimulations in the mouse primary and tumor Leydig cells (Mei et al. 2013, Wang et al. 2015). Nevertheless, the acutely inhibitory effects of kisspeptin-10 treatment on the testosterone and estradiol productions in the frog testis explants have been described (Chianese et al. 2017). By contrast, kisspeptin-10 directly increases testosterone production in the primary horse Leydig cells (Petrucci et al. 2020). Due to the divergent results of the kisspeptin influence on steroid hormone productions, this concept needed further studies to clarify its role in steroidogenesis. More importantly, the human male patients with inactivating mutations in KISS $1 R$ gene were completely irresponsive to gonadotropin treatment for stimulating testosterone secretion (Semple et al. 2005, Nimri et al. 2011), suggesting that testicular KISS1R signaling locally interacts with LHCGR signaling, and is crucial for steroidogenesis.

In the present study, we hypothesized that the autocrine action of kisspeptin is involved in regulating steroidogenesis in mouse Leydig cells. At first, we examined whether the $\mathrm{LH}$-induced kisspeptin expression depended on CAMP/PKA/CREB signaling pathway. Next, we investigated the possible regulations of kisspeptin and KISS1R on steroidogenesis by manipulating cellular Kiss 1 or Kiss1r expressions endogenously and exogenously.

\section{Materials and methods}

\section{Reagents, compounds and antibodies}

Recombinant human chorionic gonadotropin (hCG, C1063) and gelatin (G1890) were purchased from Sigma-Aldrich. 8-Bromo-cAMP sodium salt (8-Br-cAMP), Forskolin, 3-Isobutyl1-methylxanthine (IBMX) and $\mathrm{H} 89$ were purchased from Tocris Bioscience (Bristol, UK). Synthesized mouse kisspeptin-10 was purchased from Kelowna International Scientific (Taipei, Taiwan). All nucleotide primers were obtained from Genomics (Taipei, Taiwan). Predesigned siGENOME SMARTpool siRNAs, against mouse Creb1 (\#M-040959-01), Kiss1 (\#M-05764001 ) and Kiss1r (\#M-059823-01), were purchased from GE Healthcare. Lipofectamine RNAiMAX, Lipofectamine 3000, pcDNA3.1(+) vector, Restore Stripping Buffer and goat antirabbit IgG HRP antibody ( $\# 31460$ ) were purchased from Thermo Fisher Scientific. Anti-kisspeptin antibody (PAC559Mu01) was purchased from Cloud-Clone Corp. (Houston, USA) and the antibody validation was shown in Supplementary Fig. 1 (see section on supplementary materials given at the end of this article). Anti-CREB (\#9197), anti-phospho-CREB(Ser133) (\#9198), anti-StAR (\#8449), and anti-GAPDH (\#2118) antibodies were purchased from Cell Signaling Technology, Inc. Anti- $\beta$-actin antibody (sc-47778) and goat anti-mouse IgG HRP antibody (sc-2005) were purchased from Santa Cruz Biotechnology. The chemicals used in medium and buffer preparations without specific mention were purchased from Sigma-Aldrich or Merck Millipore.

\begin{abstract}
Animals
Male imprinting control region (ICR) mice, purchased from the Laboratory Animal Center, College of Medicine, National Taiwan University, were maintained in a $12 \mathrm{~h}$ light: $12 \mathrm{~h}$ darkness cycle at $25 \pm 2{ }^{\circ} \mathrm{C}, 50-70 \%$ relative humidity environment, and provided a chow diet and water ad libitum for the duration of the study. Five adult mice, 12- to 16-weekold, were used in the experiment of primary Leydig cell culture. All animal experimental procedures were conducted in accordance with the Guide for the Care and Use of Laboratory Animals and were approved by the Institutional Animal Care and Use Committee of National Taiwan University (IACUC No.: NTU-100-EL-102).
\end{abstract}

\section{Primary mouse Leydig cell isolation and culture}

The mouse testis tunica albuginea were removed and the testicular contents were washed once with Hanks' balanced salt solution (HBSS). Next, the testicular contents were transferred to fresh $10 \mathrm{~mL}$ HBSS in centrifuge tube and dissociated by shaking the tubes with hand for five to ten times. The dissociated tissues were passed through a cell strainer, and interstitial cells were suspended in the filtrate. The crude Leydig cells were collected by centrifugation at $300 \mathrm{~g}$ for $5 \mathrm{~min}$, and resuspended in serum-free Medium 199 (SigmaAldrich). In the experiment of hCG dose-response, the crude Leydig cells were counted and seeded on 12-well culture plate with $2 \times 10^{5}$ cells/well, and then treated with hCG for 8 hours. The cell lysates and media were collected for further analyses.

\section{Cell line culture}

MA-10 cell was purchased from American Type Culture Collection (ATCC; \#CRL-3050) and cultured in DMEM/F-12 medium (Sigma-Aldrich) supplemented with 15\% horse serum (Thermo Fisher Scientific), penicillin-streptomycin, and additional $20 \mathrm{mM}$ HEPES as ATCC instruction described. The culture plates or flasks were coated with $0.1 \%$ sterile gelatin solution for at least $1 \mathrm{~h}$ before using. The cells were maintained at $37^{\circ} \mathrm{C}$ with $5 \% \mathrm{CO}_{2}$. In the general experiments, the cells were counted and seeded on 24-well culture plate with 1.25 or $1.6 \times 10^{5}$ cells/well for Western blotting and progesterone releasing assay, or on 12 -well culture plate with $2.5 \times 10^{5}$ cells/ well for real-time PCR analysis. After 24-48 h post-seeding, the cells were treated with the different indicated materials for 4 or $8 \mathrm{~h}$ in the fresh complete growth media. At the end of treatment, the media were collected for progesterone measurement, and the cell lysates were collected for Western blotting or real-time PCR analyses.

In the gene knockdown experiments, $10 \mu \mathrm{M}$ siRNA for the indicated genes were reverse-transfected into the MA-10 cell 
using Lipofectamine RNAiMAX reagent. For the experiments in exogenous gene expression, the indicated plasmids were transfected into the MA-10 cell using Lipofectamine 3000 reagent. Transfection procedures were carried out following manufacture's protocol.

\section{Plasmid construction}

The insert DNA fragments were amplified by using Phusion High-Fidelity DNA Polymerase (Thermo Fisher Scientific) and further cut the $5^{\prime}$ and $3^{\prime}$ ends by using FastDigest Restriction Enzymes (Thermo Fisher Scientific). The DNA fragment ligation was under a molar ratio of $1: 3$ vector to insert with T4 DNA Ligase (Takara Bio Inc.) at $16^{\circ} \mathrm{C}$ for $1 \mathrm{~h}$. The ligated plasmid was transferred to DH5 $\alpha$ competent cell ECOS ${ }^{\text {тм }} 101$ (Yeastern Biotech Co., Ltd, Taipei, Taiwan) and further selected the bacterial clones under antibiotic-containing agar plates. In this study, the indicated genes were inserted into pcDNA3.1(+) mammalian expression vector between EcoRI and Xbal sites. pcDNA3.1(+)-EGFP contains the reporter gene, enhanced green fluorescent protein (EGFP); pcDNA3.1(+)-Kiss1-T2AGFP contains the coding sequences of ICR mouse Kiss 1, Thoseaasigna virus 2A (T2A) element, and EGFP reporter. pcDNA3.1(+)-hLHCGR contains the coding sequences of human Lhcgr, subcloned from LHCGR-Tango plasmid (\#66417, Addgene, Watertown, USA).

\section{Western blotting}

The cultured cells were rinsed with cold PBS once and lysed with $1 \times$ Laemmli buffer containing $50 \mathrm{mM}$ dithiothreitol on the ice, and further heated at $98^{\circ} \mathrm{C}$ for $10 \mathrm{~min}$ to achieve protein denaturation. The cell lysates were then subjected to $10 \%$ or $13 \%$ Tris-Glycine SDS-PAGE electrophoresis, and then transferred to PVDF membranes. The membrane was blocked with $5 \%$ non-fat milk for $1 \mathrm{~h}$ and then incubated with primary antibody in TBS containing $0.1 \%$ Tween-20 (TBST) containing $1 \% \mathrm{BSA}$ at $4{ }^{\circ} \mathrm{C}$ overnight. After washing in TBST, the membrane was incubated for $1 \mathrm{~h}$ at room temperature with horseradish peroxidase (HRP)-conjugated secondary antibody in TBST with 5\% non-fat milk. After washing in TBST three times, signals were detected by ECL (GE Healthcare) using a ChemiDoc ${ }^{\text {TM }}$ Imaging System (Bio-Rad Laboratories, Inc.). For detection of internal control protein, the same membrane was incubated with stripping buffer for $20 \mathrm{~min}$ at room temperature, and reprobed with internal control primary antibody. The protein levels were determined by obtaining the signal density in a defined area using Image Lab version 6.0 (Bio-Rad Laboratories, Inc.) or ImageJ version 1.49b (NIH).

\section{Enzyme-linked immunosorbent assay (ELISA)}

Medium progesterone and testosterone concentrations were determined using the direct competitive enzyme immunoassay (Wu et al. 2000). Briefly, $50 \mu \mathrm{L}$ diluted sample aliquot and 150 $\mu \mathrm{L}$ diluted HRP-conjugated progesterone solution (Fitzgerald Industries International, Acton, MA, USA) were added to microtiter plates, which had coated with anti-progesterone antibody (G-7 clone). For testosterone measurement, anti- testosterone antibody and HRP-conjugated testosterone (Cosmo Bio Co., Tokyo, Japan) were used in the assay. After incubation for 20-40 $\mathrm{min}$ at room temperature with gentle shaking, the plates were washed three times with washing buffer $(0.01 \mathrm{M}$ phosphate buffer containing $0.1 \%$ Tween-20, pH 7.0). Color was developed for 20-40 min by using substrate solution, $0.1 \mathrm{M} \mathrm{pH}$ 6.0 phosphate buffer containing $3.7 \mathrm{mM}$ o-phenylenediamine and $0.03 \% \mathrm{H}_{2} \mathrm{O}_{2}$. Reaction was stopped by the addition of $50 \mu \mathrm{L} 8 \mathrm{~N}$ sulfuric acid solution. Absorbance was determined using a dual-wavelength reader at 490/630 nm. All standards and samples were assayed in duplicate. The detection limits of progesterone and testosterone assays were 104 and $52 \mathrm{pg} / \mathrm{mL}$, respectively. The intra- and inter-assay coefficients of variation were 8.5 and $8.6 \%$ in the progesterone assay; 3.5 and $6.7 \%$ in the testosterone assay, respectively. The sample dilution ratios were adjusted appropriately to range within the standard curves.

\section{RNA extraction and reverse transcription}

Total RNA was extracted from the cells with TRIsure reagent (Bioline Inc., London, UK) according to the manufacturer's instructions. The cDNA was reverse-transcribed from RNA by using PrimeScript ${ }^{\mathrm{TM}}$ RT reagent Kit (Takara Bio Inc.). 500 ng total RNA was mixed with 25 pmol oligo dT primer, 50 pmol random hexamers, PrimeScript RT enzyme mix and reaction buffer, then incubated at $37^{\circ} \mathrm{C}$ for $30 \mathrm{~min}$. The reverse transcriptase was inactivated by heating to $85^{\circ} \mathrm{C}$ for $10 \mathrm{~s}$, and CDNA products were stored at $4^{\circ} \mathrm{C}$ for further analysis.

\section{Quantitative real-time PCR}

Relative levels of target mRNA were examined with the QuantStudio 3 Real-Time PCR System (Thermo Fisher Scientific) according to the manufacturer's instructions. Transcripts were quantified using the Fast SYBR Green Master Mix (Thermo Fisher Scientific) in a total volume of $10 \mu \mathrm{L}$, containing $0.4 \mu \mathrm{M}$ each primer. Primer pairs were designed on different exons; the primer sequences are shown in Table 1. Samples were initially heated for $20 \mathrm{~s}$ at $95^{\circ} \mathrm{C}$, followed by 40 cycles of $3 \mathrm{~s}$ at $95^{\circ} \mathrm{C}$ for denaturation, and $30 \mathrm{~s}$ at $60^{\circ} \mathrm{C}$ for annealing and extension. Relative gene expression values were normalized with respect to those of the internal control (Rp/19), and presented as the fold-change compared to that of control group.

\section{Statistical analysis}

Quantitative data were analyzed by two-tailed Student's $t$-test or one-way ANOVA followed by Duncan's method. Data were expressed as means \pm S.E.M. Or S.D. All statistical analyses of data were performed using Sigma Plot Software (Systat Software, San Jose, CA, USA) or Microsoft Excel (2016).

\section{Results}

\section{hCG stimulates kisspeptin expression in Leydig cells}

To address the concept that LH could trigger kisspeptin expression in Leydig cells, a dose-response of hCG on 
Table 1 Primers used in quantitative real-time PCR analysis.

\begin{tabular}{|c|c|c|c|c|}
\hline \multirow[b]{2}{*}{ Target gene } & \multicolumn{2}{|c|}{ Primer Sequence $\left(5^{\prime}-3^{\prime}\right)$} & \multirow[b]{2}{*}{ Product size (bp) } & \multirow[b]{2}{*}{ Accession number } \\
\hline & Forward & Reverse & & \\
\hline Kiss1 & TGСTGСTTCTCСTCTGTGTCGC & CAGGCTTGCTCTCTGCATACCGC & 139 & NM_178260.3 \\
\hline Kiss $1 r$ & GTGCAAATTCGTCAACTACATCC & AGCGGGAACACAGTCACATAC & 103 & NM_053244.5 \\
\hline Rp/19 & GСTCTTTCСTTTCGСTGCTGC & CAGTCACAGGCTTGCGGATGAT & 200 & NM_009078.2 \\
\hline Creb1 & CAGTGCCAACCCCCATTTAC & ACCCCATCCGTACCATTGTT & 97 & NM_001037726.1 \\
\hline Lhcgr & GCCCGACTATCTCTCACСТATC & CСTTTCCAGGGAATCACTCTGA & 111 & NM_013582.2 \\
\hline Star & AGCATGTTCCTCGCTACGTT & GCACAGCTTGGTGCCTTAATC & 88 & NM_011485.4 \\
\hline Cyp11a1 & TGGCACACAGAAAATCCATTACC & TTGGGGTCCACGATGTAAACT & 108 & NM_019779.3 \\
\hline Hsd3b1 & TTTGCTCTCTCAGTTGTGACCA & GCCTGCTTCGTGACCATATTTATT & 134 & NM_008293.3 \\
\hline
\end{tabular}

primary mouse Leydig cells was performed (Fig. 1). The protein level of kisspeptin precursor was significantly increased after hCG treatment. The increased StAR protein level and medium testosterone concentration represent the effectiveness of hCG treatment in the primary cells.

The CAMP/PKA/CREB signaling pathway, a downstream of LHCGR, may mediate hCG-stimulated kisspeptin expression in Leydig cell. Based on the ChIP-seq experiment, CREB is a potential transcription factor to regulate mouse Kiss 1 gene expression (Yevshin et al. 2019). Supporting with this idea, in the primary mouse Leydig cells, CREB Ser133 phosphorylation was significantly increased after hCG treatment (Fig. 1A and B). To confirm the hypothesis, MA-10 cell, a mouse Leydig tumor cell line, was used for the following experiments due to good performance in cell transfections. Treatments of forskolin (Fsk), an adenylyl cyclase activator, plus 3-isobutyl-1-methylxanthine (IBMX), a phosphodiesterase inhibitor, elevated intracellular CAMP level and triggered robust Kiss 1 expression, which is completely blocked by PKA inhibitor H89
(Fig. 2A). Knockdown of Creb1 significantly inhibits Fsk/IBMX-induced Kiss 1 expression (Fig. 2B). Similar results were observed in the PKA activator 8-Br-cAMPtreating experiment, which shown that Kiss 1 level in Creb1-knockdowned cells was significantly lower than the control cells after stimulation (data not shown). Furthermore, at the protein level, knockdown of Creb1 diminishes hCG-induced kisspeptin expression (Fig. 2C and D). The previously described results suggest that Kiss 1 expression is regulated by cAMP/PKA/CREB signaling pathway in mouse Leydig cells.

\section{$K I S S 1 R$ regulates basal and $h C G$-stimulated steroidogenesis}

Before carrying out the later experiments, we tested whether serum deprivation altered cellular states and further changed the outcomes since most of steroidogenesis-related experiments were achieved in the serum-free condition for many years. As the results shown in Fig. 3, serum deprivation significantly increased Kiss 1 expression but inhibited 8-Br-cAMP induction;
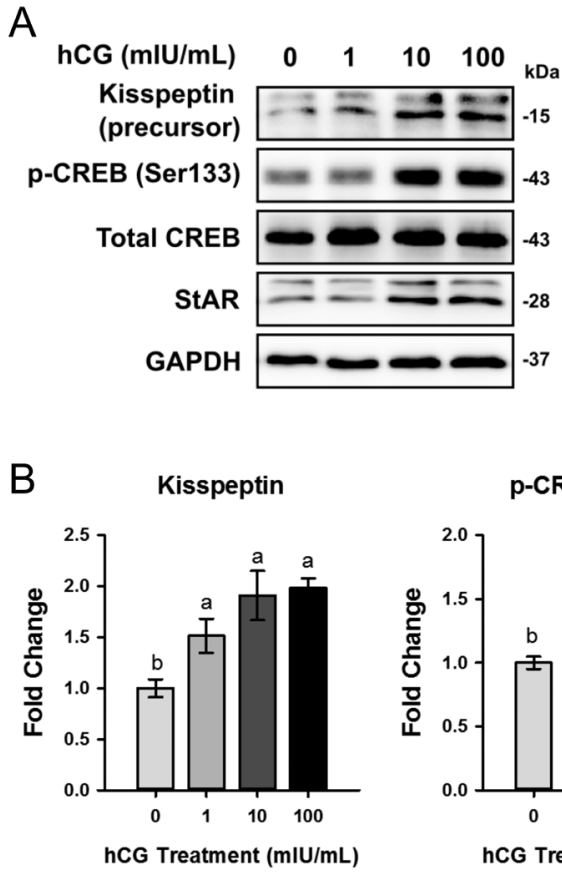

Reproduction (2020) 160 843-852
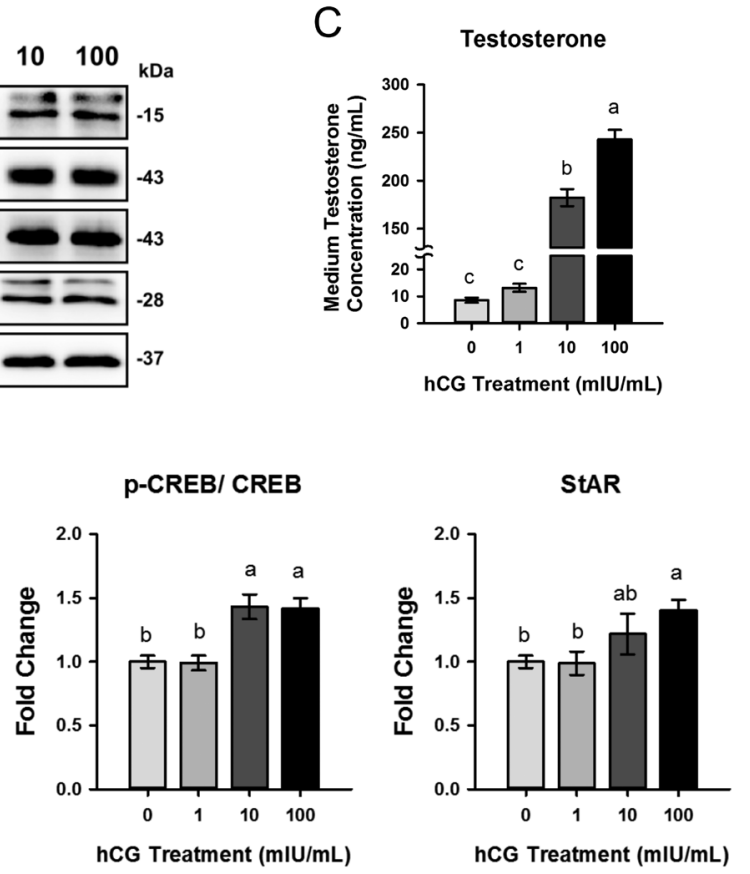

Figure 1 hCG stimulates kisspeptin expression in mouse Leydig cells. Primary mouse Leydig cells were treated with the different concentrations of hCG for $8 \mathrm{~h}$, and then the samples were collected for analyzing the specific protein levels and steroidogenesis. (A) Representative immunoblots of kisspeptin, StAR, and phospho-CREB (Ser133) from the hCG-treated Leydig cells are shown. (B) Densitometric analyses of Western blotting data from panel A. GAPDH and total CREB were used as the loading controls. (C) At the end of treatment, testosterone concentrations from the culture media were measured. Data are represented as means \pm S.E.M. $(n=5)$. Bars with different letters are significantly different by using Duncan's method $(P<0.05)$. 

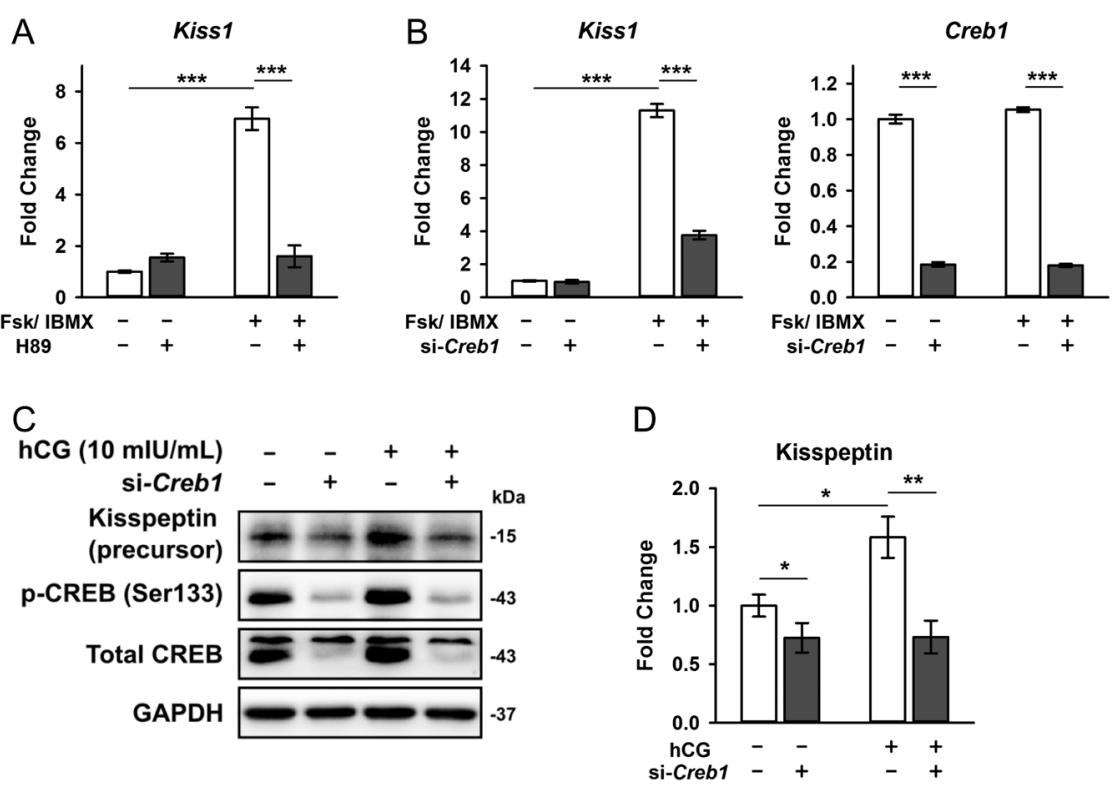

Figure 2 The regulation of kisspeptin expression involves cAMP/PKA/CREB pathway in Leydig cells. (A) MA-10 cells, mouse Leydig tumor cell line, were pre-treated with $50 \mu \mathrm{M}$ $\mathrm{H} 89$ for $1 \mathrm{~h}$, and then treated with $50 \mu \mathrm{M}$ Forskolin (Fsk)/100 $\mu \mathrm{M}$ IBMX for further $8 \mathrm{~h}$. The Kiss 1 mRNA level was measured by real-time PCR. For the relative comparison of real-time PCR data, Rp/19 was used as the internal controls. (B) MA-10 cells were first transfected with Creb1 siRNA for $48 \mathrm{~h}$, and then treated with Fsk/ IBMX for 8 h. The Kiss 1 and Creb1 mRNA levels were measured by real-time PCR. (C) MA-10 cells were transfected with Creb1 siRNA. After $48 \mathrm{~h}$, the cells were treated with $10 \mathrm{mIU} / \mathrm{mL}$ hCG for 4 $h$ and cell lysates were analyzed by immunoblots (D) Densitometric analyses of immunoblotting data of kisspeptin from panel C. Data are represented as means \pm S.E.M. $(n=3) .{ }^{*} P<0.05,{ }^{* *} P<0.01,{ }^{* * *} P<0.001$. on the other hand, Kiss1r mRNA level in the same experiment displayed opposite expression pattern. Since serum deprivation greatly affected gene expressions and cell responses, the following experiments were performed in the complete growth media.

To examine the direct effect of kisspeptin on steroidogenesis, we designed two experiments having different kisspeptin-exposing periods. For testing the acute effect, MA-10 cells were treated with different concentrations of mouse kisspeptin-10 for $4 \mathrm{~h}$ (Fig. 4A). For testing the chronic effect, a 2-day exposure, the cells were transiently transfected with mouse Kiss 1-expressing plasmid and secreted kisspeptin continuously (Fig. $4 \mathrm{~B})$, in view of that kisspeptin-10 would be degraded rapidly by serum proteinases in the culture medium and wasn't suitable for a long-term treatment (Takino et al.
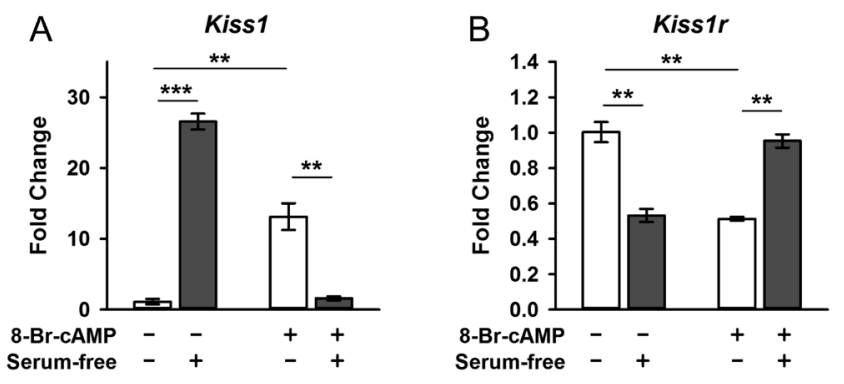

Figure 3 Serum deprivation disrupts gene expressions and cell responses in MA-10 cells. The cells were seeded and cultured in the complete growth medium for 2 days. For the serum deprivation test, the media were replaced with fresh complete growth or serum-free media containing DMSO or $100 \mu \mathrm{M} 8$-Br-cAMP as indicated, and the cells were cultured for a further $8 \mathrm{~h}$. The Kiss 1 (A) and Kiss $1 \mathrm{r}$ (B) mRNA levels were measured by real-time PCR. For the relative comparison of real-time PCR data, Rp/19 was used as the internal controls. Data are represented as means \pm S.E.M. $(n=3)$. ${ }^{*} P<0.05$, ${ }^{* *} P<0.01,{ }^{* * *} P<0.001$
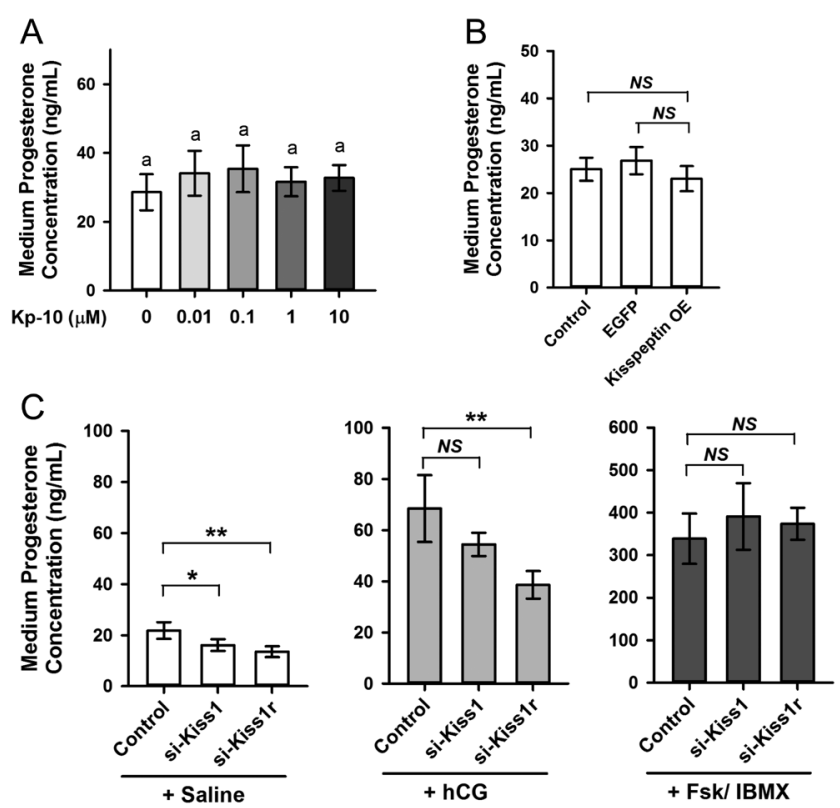

Figure 4 KISS1R regulates the basal and hCG-stimulated steroidogenesis. To investigate the steroidogenic regulations of kisspeptin and KISS1R on MA-10 cells, the post-treated media from the following experiments were analyzed for progesterone concentrations by using ELISA. (A) MA-10 cells were treated with different concentrations of mouse kisspeptin-10 (Kp-10) for $4 \mathrm{~h}$. (B) MA-10 cells were transiently transfected with pcDNA3.1(+)-EGFP (EGFP), or pcDNA3.1(+)-mKiss1-T2A-EGFP (Kisspeptin OE) plasmids, or added only with transfection reagent (control). The basal steroidogenesis in different groups were examined post-2-day transfection. (C) MA-10 cells were transiently transfected with the indicated siRNAs. After 2 days, the cells were treated with saline, 100 $\mathrm{mIU} / \mathrm{mL}$ hCG, or $50 \mu \mathrm{M}$ Fsk/ $100 \mu \mathrm{M}$ IBMX for $4 \mathrm{~h}$. Data are represented as means \pm S.D. $(n=4)$. Bars with different letters are significantly different by using Duncan's method $(P<0.05)$. ${ }^{*} P<$ $0.05, * * P<0.01$. NS, not significant. 
2003, Liu et al. 2013). In both conditions, the medium progesterone concentrations did not change significantly when compared to their own control group.

In regard to the putatively autocrine action of kisspeptin, the cells may be in a steady state that they could not respond to additional kisspeptin stimulations. To break down the autocrine action, suppressing endogenous Kiss 1 or Kiss $1 r$ expressions by siRNAs was performed. Kiss $1 r$-knockdowned MA-10 cells significantly decreased progesterone production in both basal (saline) and hCG-treated conditions (Fig. 4C). However, knockdown of Kiss 1 only showed a slight effect on progesterone production. This may be caused by the technical limitations of siRNA transfection that the partial cells were not transfected and kept lowlevel kisspeptin in the culture media. Considering the potential effects of Kiss 1 or Kiss1r knockdown on cell proliferation, we tested the cell viability by sulforhodamine $B$ assay, and the results shown no difference in all groups after siRNA transfection (data not shown). The previously described results indicate that KISS1R signaling is important in regulating both basal and hCG-stimulated steroidogenesis. Interestingly, the suppressive effect of Kiss $1 r$ knockdown on progesterone production was only found in hCG-treated but not Fsk/IBMX-treated (Fig. 4C) or 8-Br-cAMP-treated (data not shown) conditions, suggesting that KISS1R signaling may regulate the steroidogenic pathway between LHCGR and adenylyl cyclase.

\section{Lack of KISS1R does not diminish the cellular CYP11A1 and HSD3B activities}

Since Kiss1r knockdown directly affects basal progesterone production, we assumed that lack of KISS1 R function might cause steroidogenic enzyme deficiency. In the steroidogenesis-related gene expression profiles, the mRNA levels of Lhcgr, Star and Cyp11a1 were significantly decreased in the Kiss $1 r$-knockdowned MA-10 cells (Fig. 5A). We had checked the Kiss $1 r$ siRNA sequences, which did not match with mouse Lhcgr, Star and Cyp11a1 mRNAs by using global alignment, thus excluding the possibility of off-target effects on the interested genes by siRNA transfection. Next, to further verify steroidogenic enzyme functions in the cells, we performed the enzyme-activity assay, supplied different cholesterol-derivative substrates in the culture media and further analyzed progesterone concentrations. $22 \mathrm{R}$-hydroxycholesterol (22R-OHC) is catalyzed to progesterone by the activities of CYP11A1 and HSD3B; pregnenolone is converted directly by HSD3B. As the results shown in Fig. 5B, the progesterone production did not decrease in the Kiss $1 r$-knockdowned cells when given the indicated substrates in either basal or hCGtreated conditions, which demonstrates that KISS1Rdeficit-induced steroidogenic deficiency did not result from insufficient activities of either CYP11A1 or HSD3B.

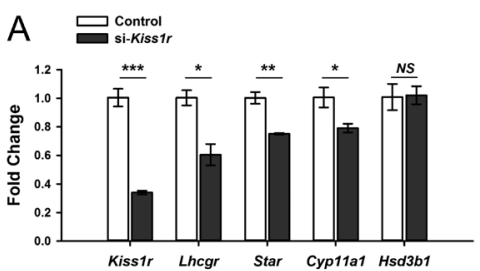

B
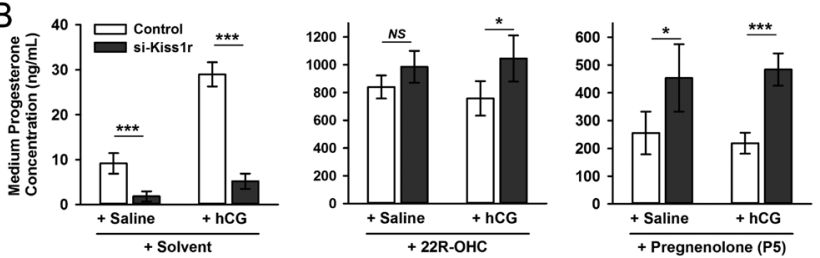

Figure 5 Lack of KISS1R does not diminish the cellular CYP11A1 and HSD3B activities. (A) MA-10 cells were transiently transfected with the Kiss $1 r$ siRNA. After 2 days, the steroidogenesis-related gene expressions were analyzed by real-time PCR. Rp/19 was used as the internal controls. Data are represented as means \pm S.E.M. $(n=3)$. (B) MA-10 cells were transiently transfected with the Kiss $1 r$ siRNA. After 2 days, the cells were treated with saline or $100 \mathrm{mIU} / \mathrm{mL} \mathrm{hCG}$, combined with different cholesterol-derivative substrates, $10 \mu \mathrm{g} / \mathrm{mL}$ 22R-hydroxycholesterol (22R-OHC) or $1 \mu \mathrm{g} / \mathrm{mL}$ pregnenolone (P5), or $0.1 \%$ ethanol (solvent). The media were collected after $4-\mathrm{h}$ treatment and analyzed by ELISA. Data are represented as means \pm S.D. $(n=5)$. ${ }^{*} P<0.05,{ }^{* *} P<0.01,{ }^{* * *} P<0.001$. NS, not significant.

\section{KISS1R maintains hCG sensitivity by regulating Lhcgr expression}

Based on the previous results, the Kiss 1 r-knockdowned MA-10 cells were evidently desensitized to hCG stimulation, which was contributed to the functional failure in the steroidogenic pathway between LHCGR and adenylyl cyclase (Fig. 4C). Furthermore, in the gene expression profiles, the Lhcgr expression in the Kiss $1 r$-knockdowned cells was significantly decreased compared to control cells (Fig. 5A). These evidences reveal that KISS1R functions involve the regulation of Lhcgr expression, and, importantly, hCG desensitization in KISS1R-deficient cells may be caused by insufficient LHCGR level. Consisting with our hypothesis, the results showed that exogenous human LHCGR (hLHCGR) expression obviously rescued the steroidogenic function from the Kiss1r-knockdowned cells (Fig. 6). In the hCG-treated condition, both progesterone production and StAR protein level were significantly lower in Kiss $1 r$-knockdowned cells than in control cells (EGFP), and these outcomes were reversed by expressing hLHCGR. However, in the saline-treated condition, the progesterone production in Kiss $1 r$-knockdowned cells was not fully recovered by exogenous hLHCGR (Fig. 6C), which means that other factors, such as StAR, for the basal steroidogenesis were changed due to KISS1R deficiency. Taken together, the previously described results suggest that functions of KISS1R signaling in Leydig cell at least include maintaining LH sensitivity through regulating Lhcgr expression. 
A

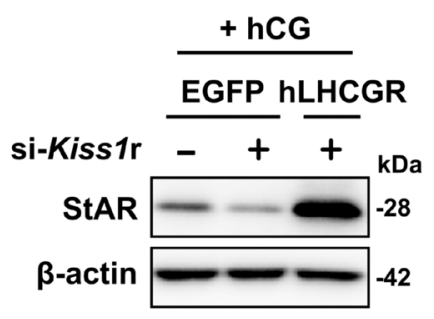

B

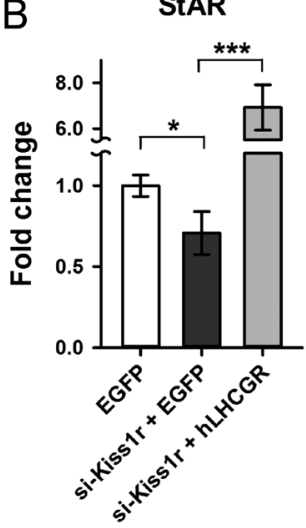

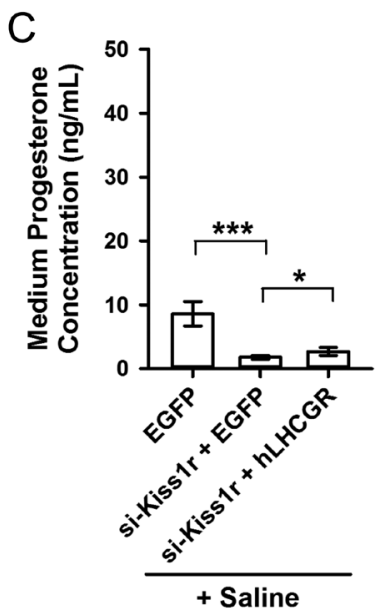

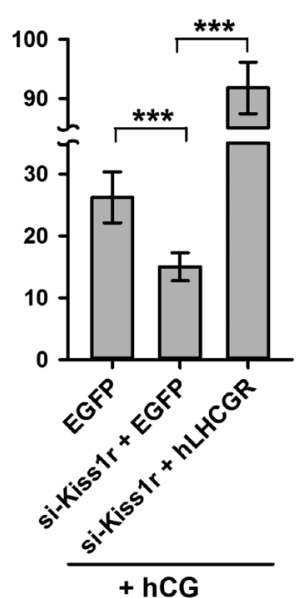

Figure 6 Exogenous expression of human luteinizing hormone receptor (hLHCGR) rescues steroidogenesis on Kiss $1 r$-knockdowned MA-10 cells. (A) MA-10 cells were transiently transfected with the Kiss $1 r$ siRNA, pcDNA3.1(+)-EGFP (EGFP, transfection control) or pcDNA3.1(+)-hLHCGR (hLHCGR) plasmids as indicated. After $48 \mathrm{~h}$, the cells were treated with $100 \mathrm{mIU} / \mathrm{mL}$ hCG for $4 \mathrm{~h}$ and cell lysates were analyzed by immunoblots. (B) Densitometric analyses of immunoblotting images from panel A. Data are represented as means \pm S.E.M. $(n=3)$. (C) The cells were treated as same as panel A description, and the post-treated media were analyzed for progesterone concentrations by ELISA. Data are represented as means \pm S.D. $(n=5) .{ }^{*} P<0.05, * * * P<0.001$. NS, not significant.

\section{Discussion}

The role of kisspeptin, a crucial neuropeptide for stimulating GnRH secretion to initiate puberty and control the reproductive activity, has been well-established in the mammalian physiology (de Roux et al. 2003, Funes et al. 2003, Seminara et al. 2003, Kirilov et al. 2013). Beyond the central neuroendocrine regulation, the other functions of kisspeptin in peripheral tissues, including pancreas, bone, ovary and kidney, are suggested (Yi et al. 2010, Dorfman et al. 2014, Song et al. 2014, Son et al. 2018). In the current study, we propose a putative model that testicular kisspeptin modulates steroidogenesis via an autocrine signaling loop on the mouse Leydig cell. In this model, LH stimulates Leydig cell to generate kisspeptin, which depends on the cAMP/PKA/CREB pathway. The secreted kisspeptin further acts on the same cells to regulate testosterone production; this regulation involves two aspects, basal steroidogenesis and gonadotropin sensitivity, through conducting Star and Lhcgr expressions. In the physiological view, this autocrine action of kisspeptin may allow Leydig cell to amplify and prolong LH signal, and, particularly, maintain LH sensitivity.

Based on the mouse Leydig cell model, hCG and PKA activators were able to induce kisspeptin expression, indicating that Leydig cell is one of the sources of testicular kisspeptin production triggered by LH signal. Supporting this idea, previous reports have shown that gonadotropin could stimulate Kiss 1 expression in the primary mouse and goat Leydig cells (Salehi et al. 2015, Samir et al. 2018). We also demonstrated that testicular Kiss 1 expression was synchronizing with Lhcgr expression as well as testis growths (Wang et al. 2015). In addition to the postnatal mouse model, the cycles of testicular development and regression in the seasonal breeding animals provided another valuable model to examine this idea. Hamsters are seasonal breeding animals, and the activity of reproductive system depends on the photoperiod. At the long photoperiod, the endocrine and spermatogenic functions of testes were active. In contrast, at the short photoperiod, these functions were suppressed; this testicular regression is a consequence of the reduced release of gonadotropins (Siegel, 1985). Consistent with this concept, in the striped hamster, the testicular Kiss 1 expression was significantly decreased at the short photoperiod (Li et al. 2015). A similar observation was described in the nonmammalian model, anuran amphibian, which showed increased testicular kisspeptin protein level in the breeding season (Chianese et al. 2017).

CREB-deficient Leydig cells failed in Kiss 1 expression induced by either hCG or Fsk/IBMX treatments, suggesting that CREB is a critical transcription factor for gonadotropin-induced Kiss 1 expression (Fig. 2). Supporting this concept, the significance of cAMP/PKA/ CREB pathway in activating Kiss 1 gene transcription was found in other cell types, including Kiss 1 neuron and hepatocyte (Song et al. 2014, Treen et al. 2016). The novel peptide phoenixin, discovered as a potential upstream regulator of mouse Kiss 1 neuron, is able to simulate Kiss 1 expression, which was greatly suppressed by pre-treating cAMPS-Rp, a competitive antagonist of PKA (Treen et al. 2016). Apart from the neuron, hepatocytes also produce kisspeptin via activating this pathway (Song et al. 2014). The raising intracellular cAMP concentrations, induced by either glucagon or Fsk/IBMX treatments, promoted Kiss 1 expression in mouse hepatocytes. Additionally, in the luciferase reporter assay, the Fsk/IBMX-stimulated Kiss 1 transcriptional response was obviously suppressed by the mutations of two putative cAMP response element (CRE) sites on the Kiss 1 promoter. Furthermore, a prior 
report indicated that the disruption of CREB-regulated transcription coactivator-1 (Crtc1) gene resulted decreasing Kiss 1 mRNA levels in the hypothalamic cells (Altarejos et al. 2008). These observations provide strong evidences to support that CREB acts as a key regulator to mediate Kiss 1 gene transcription.

This is the first report to describe that KISS1 R signaling is crucial for maintaining gonadotropin sensitivity in the Leydig cells through regulating Lhcgr expression (Figs 4 and 5). This finding could explain why the male patients with loss-of-function mutations (C233R or F272S) in KISS1R gene show severe gonadotropin insensitivity (Semple et al. 2005, Nimri et al. 2011). In the repeated stimulation tests, most patients failed to show increased testosterone levels after short and prolonged hCG administrations, performed repeatedly in different ages from infancy to early adulthood. In the mouse model, a recent study indicated that lack of KISS1R in testis resulted insufficient testicular functions (Leon et al. 2016). The male Kiss $1 r^{-/} \mathrm{Tg}$ (aka Gpr54 ${ }^{-/-} \mathrm{Tg}$ in Leon's study) rescued mice, which were the global Kiss $1 r$ null mice had selective re-introduction of Kiss $1 r$ expression in the $\mathrm{GnRH}$ neurons to preserve gonadotropic axis activity, shown the incomplete growths in testes and epididymes, and the appearance of multinucleated giant cells and apoptotic germ cells in the seminiferous tubules. Interestingly, these male $\mathrm{Kiss}_{1} \mathrm{r}^{-/-} \mathrm{Tg}$ rescued mice also showed lower testosterone:LH ratio, which had similar testosterone levels but approximately 2.2fold higher LH levels compared to WT mouse data, suggesting that the Leyding cells in those rescued mice were desensitized to gonadotropin stimulation. Furthermore, KISS1R signaling may be important in maintaining neurotransmitter sensitivity in the hypothalamic or pituitary neurons. In the same report, Kiss $1 r$ null mice were extremely irresponsive to different neurotransmitter analog stimulations on LH secretion, which was recovered obviously in $\mathrm{Kiss} 1 \mathrm{r}^{-1-} \mathrm{Tg}$ mice (Leon et al. 2016). Similar results were found in the Kiss 1 null rats, which failed to elicit LH secretion after monosodium glutamate, NMDA and norepinephrine administrations (Uenoyama et al. 2015). Regarding the transcriptional regulations between KISS1R and LHCGR found in this study, we assumed that KISS1R signaling might be mandatory for some neurotransmitter receptor expressions on $\mathrm{GnRH}$ neuron or its downstream neurons.

The fact that serum deprivation caused a remarkable disturbance in Kiss 1 expression was an unexpected finding (Fig. 3). A prior report suggested that serum deprivation induces strong and temporal CREB phosphorylation (Leicht et al. 2001), which may explain the result of robust Kiss 1 expression. However, this outcome was disrupted when combining PKA agonist treatment and serum deprivation, which reveals that other factors derived from serum and their downstream signaling pathways affect PKA/CREB-dependent Kiss 1 transcription. AMP-activated protein kinase (AMPK), an intracellular energy sensor and signaling regulator, mediating Kiss 1 expression in both Kiss 1 neuron and GT1-7 neural cell line had been reported (Wen et al. 2012, Roa et al. 2018); this finding might associate with the results we observed since serum contains plentiful nutrients, growth factors and hormones. Importantly, in addition to CREB, the roles of numerous transcription factors (Yevshin et al. 2019) on regulating Kiss 1 expression either positively or negatively haven't been characterized well. Therefore, studies focused on Kiss 1 transcriptional regulation and its molecular mechanism are needed.

In the past, the experiments for studying steroidogenesis were usually examined in a serum-free condition because serum contains various and undetermined factors that influenced steroidogenic function (Pate \& Condon 1982). However, serum deprivation undeniably disrupts cellular homeostasis at least including elevated Kiss 1 and reduced Kiss $1 r$ expressions in Leydig cells, which may account for the ineffectiveness of kisspeptin treatment in our previous studies (Hsu et al. 2014, Wang et al. 2015). This finding also suggests that researchers should cautiously design experiments and interpret the results when applying the cell line, primary cell and tissue cultures in serum-free media to study steroidogenesis.

In summary, we have shown that the cAMP/PKA/CREB signaling pathway mediates gonadotropin-induced Kiss 1 gene transcription in mouse Leydig cells. Regarding the putatively autocrine action of kisspeptin, our study also highlights the importance of KISS1R singling in maintaining gonadotropin sensitivity and steroidogenic function through regulating $\mathrm{Lhcgr}$ and the related gene expressions. This study provides new insights into the pathophysiology of gonadotropin insensitivity in idiopathic hypogonadotropic hypogonadism.

\section{Supplementary materials}

This is linked to the online version of the paper at https://doi. org/10.1530/REP-20-0328.

\section{Declaration of interest}

The authors declare that there is no conflict of interest that could be perceived as prejudicing the impartiality of the research reported.

\section{Funding}

This work was supported by the Ministry of Science and Technology (grant number 106-2320-B-002-040-MY3, 2017).

\section{Author contribution statement}

$\mathrm{M}-\mathrm{C} \mathrm{H}$ and $\mathrm{C}-\mathrm{H}$ C conceived the study and wrote the manuscript. $\mathrm{M}-\mathrm{C} \mathrm{H}$ performed experiments and analyzed data. L-S W and D-S J reviewed and edited the manuscript. 


\section{Acknowledgements}

The authors thank Dr Yi-Fan Jiang (School of Veterinary Medicine, National Taiwan University, Taiwan) and Dr Hetal V Shah (National Institute of Neurological Disorders and Stroke, National Institutes of Health, USA) for the critical reading and comments of the manuscript.

\section{References}

Altarejos JY, Goebel N, Conkright MD, Inoue H, Xie J, Arias CM, Sawchenko PE \& Montminy M 2008 The Creb1 coactivator Crtc1 is required for energy balance and fertility. Nature Medicine $\mathbf{1 4}$ 1112-1117. (https://doi.org/10.1038/nm.1866)

Chianese R, Cobellis G, Chioccarelli T, Ciaramella V, Migliaccio M, Fasano S, Pierantoni R \& Meccariello R 2016 Kisspeptins, estrogens and male fertility. Current Medicinal Chemistry 23 4070-4091. (https://doi. org/10.2174/0929867323666160902155434)

Chianese R, Ciaramella V, Fasano S, Pierantoni R \& Meccariello R 2017 Kisspeptin regulates steroidogenesis and spermiation in anuran amphibian. Reproduction 154 403-414. (https://doi.org/10.1530/REP17-0030)

Chianese R, Colledge WH, Fasano S \& Meccariello R 2018 Editorial: The multiple facets of kisspeptin activity in biological systems. Frontiers in Endocrinology 9 727. (https://doi.org/10.3389/fendo.2018.00727)

De Roux N, Genin E, Carel JC, Matsuda F, Chaussain JL \& Milgrom E 2003 Hypogonadotropic hypogonadism due to loss of function of the KiSS1 derived peptide receptor GPR54. PNAS 100 10972-10976. (https://doi. org/10.1073/pnas.1834399100)

Dorfman MD, Garcia-Rudaz C, Alderman Z, Kerr B, Lomniczi A Dissen GA, Castellano JM, Garcia-Galiano D, Gaytan F, Xu B et al. 2014 Loss of Ntrk2/Kiss1r signaling in oocytes causes premature ovarian failure. Endocrinology 155 3098-3111. (https://doi.org/10.1210/ en.2014-1111)

Funes S, Hedrick JA, Vassileva G, Markowitz L, Abbondanzo S, Golovko A, Yang S, Monsma FJ \& Gustafson EL 2003 The KiSS-1 recepto GPR54 is essential for the development of the murine reproductive system. Biochemical and Biophysical Research Communications 312 1357-1363. (https://doi.org/10.1016/j.bbrc.2003.11.066)

Gonzalez GA \& Montminy MR 1989 Cyclic AMP stimulates somatostatin gene transcription by phosphorylation of CREB at serine 133. Cell 59 675-680. (https://doi.org/10.1016/0092-8674(89)90013-5)

Han Y, Zhao Y, Si W, Jiang X, Wu J, Na R, Han Y, Li K, Yang L, Ee G et al. 2020 Temporal expression of the KISS1/GPR54 system in goats' testes and epididymides and its spatial expression in pubertal goats. Theriogenology 152 114-121. (https://doi.org/10.1016/j.theriogenology.2020.04.022)

Hansson V, Skalhegg BS \& Tasken K 2000 Cyclic-AMP-dependent protein kinase (PKA) in testicular cells. Cell specific expression, differential regulation and targeting of subunits of PKA. Journal of Steroid Biochemistry and Molecular Biology 73 81-92. (https://doi.org/10.1016/ S0960-0760(00)00057-1)

Hsu MC, Wang JY, Lee YJ, Jong DS, Tsui KH \& Chiu CH 2014 Kisspeptin modulates fertilization capacity of mouse spermatozoa. Reproduction 147 835-845. (https://doi.org/10.1530/REP-13-0368)

Hussain MA, Song WJ \& Wolfe A 2015 There is kisspeptin - and then there is kisspeptin. Trends in Endocrinology and Metabolism 26 564-572. (https://doi.org/10.1016/j.tem.2015.07.008)

Kirilov M, Clarkson J, Liu X, Roa J, Campos P, Porteous R, Schutz G \& Herbison AE 2013 Dependence of fertility on kisspeptin-Gpr54 signaling at the GnRH neuron. Nature Communications 4 2492. (https:// doi.org/10.1038/ncomms3492)

Kotani M, Detheux M, Vandenbogaerde A, Communi D, Vanderwinden JM, Le Poul E, Brezillon S, Tyldesley R, Suarez-Huerta N, Vandeput F et al. 2001 The metastasis suppressor gene KiSS-1 encodes kisspeptins, the natural ligands of the orphan G protein-coupled receptor GPR54. Journal of Biological Chemistry 276 34631-34636. (https://doi.org/10.1074/jbc. M104847200)

Leicht M, Briest W, Holzl A \& Zimmer HG 2001 Serum depletion induces cell loss of rat cardiac fibroblasts and increased expression of extracellular matrix proteins in surviving cells. Cardiovascular Research 52 429-437. (https://doi.org/10.1016/s0008-6363(01)00391-1)
Leon S, Barroso A, Vazquez MJ, Garcia-Galiano D, Manfredi-Lozano M, Ruiz-Pino F, Heras V, Romero-Ruiz A, Roa J, Schutz G et al. 2016 Direct actions of kisspeptins on GnRH neurons permit attainment of fertility but are insufficient to fully preserve gonadotropic axis activity. Scientific Reports 6 19206. (https://doi.org/10.1038/srep19206)

Li SN, Xue HL, Zhang Q, Xu JH, Wang S, Chen L \& Xu LX 2015 Photoperiod regulates the differential expression of KiSS-1 and GPR54 in various tissues and sexes of striped hamster. Genetics and Molecular Research 14 13894-13905. (https://doi.org/10.4238/2015.October.29.10)

Liu Z, Ren C, Jones W, Chen P, Seminara SB, Chan YM, Smith NF, Covey JM, Wang J \& Chan KK 2013 LC-MS/MS quantification of a neuropeptide fragment kisspeptin-10 (NSC 741805) and characterization of its decomposition product and pharmacokinetics in rats. Journal of Chromatography: B, Analytical Technologies in the Biomedical and Life Sciences 926 1-8. (https://doi.org/10.1016/j.jchromb.2013.02.027)

Manna PR, Dyson MT, Eubank DW, Clark BJ, Lalli E, Sassone-Corsi P, Zeleznik AJ \& Stocco DM 2002 Regulation of steroidogenesis and the steroidogenic acute regulatory protein by a member of the CAMP response-element binding protein family. Molecular Endocrinology $\mathbf{1 6}$ 184-199. (https://doi.org/10.1210/mend.16.1.0759)

Mei H, Doran J, Kyle V, Yeo SH \& Colledge WH 2013 Does kisspeptin signaling have a role in the testes? Frontiers in Endocrinology 4198. (https://doi.org/10.3389/fendo.2013.00198)

Messager S, Chatzidaki EE, Ma D, Hendrick AG, Zahn D, Dixon J, Thresher RR, Malinge I, Lomet D, Carlton MB et al. 2005 Kisspeptin directly stimulates gonadotropin-releasing hormone release via G protein-coupled receptor 54. PNAS 102 1761-1766. (https://doi. org/10.1073/pnas.0409330102)

Nimri R, Lebenthal Y, Lazar L, Chevrier L, PhilliP M, Bar M, HernandezMora E, De Roux N \& Gat-Yablonski G 2011 A novel loss-of-function mutation in GPR54/KISS1R leads to hypogonadotropic hypogonadism in a highly consanguineous family. Journal of Clinical Endocrinology and Metabolism 96 E536-E545. (https://doi.org/10.1210/jc.2010-1676)

Ohtaki T, Shintani Y, Honda S, Matsumoto H, Hori A, Kanehashi K, Terao Y, Kumano S, Takatsu Y, Masuda Y et al. 2001 Metastasis suppressor gene KiSS-1 encodes peptide ligand of a G-protein-coupled receptor. Nature 411 613-617. (https://doi.org/10.1038/35079135)

Pate JL \& Condon WA 1982 Effects of serum and lipoproteins on steroidogenesis in cultured bovine luteal cells. Molecular and Cellular Endocrinology 28 551-562. (https://doi.org/10.1016/03037207(82)90146-0)

Petrucci L, Maranesi M, Verini Supplizi A, Dall'Aglio C, Mandara MT, Quassinti L, Bramucci M, Miano A, Gobbetti A, Catone G et al. 2020 Kisspeptin/GnRH1 system in Leydig cells of horse (Equus caballus): presence and function. Theriogenology 152 1-7. (https://doi. org/10.1016/j.theriogenology.2020.04.006)

Roa J, Barroso A, Ruiz-Pino F, Vazquez MJ, Seoane-Collazo P, MartinezSanchez N, Garcia-Galiano D, Ilhan T, Pineda R, Leon S et al. 2018 Metabolic regulation of female puberty via hypothalamic AMPKkisspeptin signaling. PNAS 115 E10758-E10767. (https://doi. org/10.1073/pnas.1802053115)

Salehi S, Adeshina I, Chen H, Zirkin BR, Hussain MA, Wondisford F, Wolfe A \& Radovick S 2015 Developmental and endocrine regulation of kisspeptin expression in mouse Leydig cells. Endocrinology 156 1514-1522. (https://doi.org/10.1210/en.2014-1606)

Samir H, Nagaoka K \& Watanabe G 2018 Effect of kisspeptin antagonist on goat in vitro Leydig cell steroidogenesis. Theriogenology 121 134-140. (https://doi.org/10.1016/j.theriogenology.2018.07.038)

Seminara SB, Messager S, Chatzidaki EE, Thresher RR, Acierno JS, Shagoury JK, Bo-Abbas Y, Kuohung W, Schwinof KM, Hendrick AG et al. 2003 The GPR54 gene as a regulator of puberty. New England Journal of Medicine 349 1614-1627. (https://doi.org/10.1056/ NEJMoa035322)

Semple RK, Achermann JC, Ellery J, Farooqi IS, Karet FE, Stanhope RG, O'Rahilly S \& Aparicio SA 2005 Two novel missense mutations in G protein-coupled receptor 54 in a patient with hypogonadotropic hypogonadism. Journal of Clinical Endocrinology and Metabolism 90 1849-1855. (https://doi.org/10.1210/jc.2004-1418)

Sharma A, Thaventhiran T, Minhas S, Dhillo WS \& Jayasena CN 2020 Kisspeptin and testicular function-is it necessary? International Journal of Molecular Sciences 21 2958. (https://doi.org/10.3390/ijms21082958)

Siegel HI 1985 The Hamster Reproduction and Behavior. Boston, MA: Springer US: Imprint: Springer. 
Son HE, Kim KM, Kim EJ \& Jang WG 2018 Kisspeptin-10 (KP-10) stimulates osteoblast differentiation through GPR54-mediated regulation of BMP2 expression and activation. Scientific Reports 8 2134. (https://doi. org/10.1038/s41598-018-20571-2)

Song WJ, Mondal P, Wolfe A, Alonso LC, Stamateris R, Ong BW, Lim OC, Yang KS, Radovick S, Novaira HJ et al. 2014 Glucagon regulates hepatic kisspeptin to impair insulin secretion. Cell Metabolism 19 667-681. (https://doi.org/10.1016/j.cmet.2014.03.005)

Takino T, Koshikawa N, Miyamori H, Tanaka M, Sasaki T, Okada Y, Seiki M \& Sato H 2003 Cleavage of metastasis suppressor gene product KiSS-1 protein/metastin by matrix metalloproteinases. Oncogene 22 4617-4626. (https://doi.org/10.1038/sj.onc.1206542)

Treen AK, Luo V \& Belsham DD 2016 Phoenixin activates immortalized GnRH and kisspeptin neurons through the novel receptor GPR173. Molecular Endocrinology 30 872-888. (https://doi.org/10.1210/me.20161039)

Uenoyama Y, Nakamura S, Hayakawa Y, Ikegami K, Watanabe Y, Deura C, Minabe S, Tomikawa J, Goto T, leda N et al. 2015 Lack of pulse and surge modes and glutamatergic stimulation of luteinising hormone release in Kiss1 knockout rats. Journal of Neuroendocrinology 27 187-197. (https://doi.org/10.1111/jne.12257)

Wahab F, Atika B, Shahab M \& Behr R 2016 Kisspeptin signalling in the physiology and pathophysiology of the urogenital system. Nature Reviews: Urology 13 21-32. (https://doi.org/10.1038/nrurol.2015.277)

Wang JY, Hsu MC, Tseng TH, Wu LS, Yang KT \& Chiu CH 2015 Kisspeptin expression in mouse Leydig cells correlates with age. Journal of the Chinese Medical Association 78 249-257. (https://doi.org/10.1016/j. jcma.2015.01.004)
Wen JP, Liu C, Bi WK, Hu YT, Chen Q, Huang H, Liang JX, Li LT, Lin LX \& Chen G 2012 Adiponectin inhibits KISS1 gene transcription through AMPK and specificity protein-1 in the hypothalamic GT1-7 neurons. Journal of Endocrinology 214 177-189. (https://doi.org/10.1530/JOE-120054)

Wu LS, Sheu SY, Huang CC, Chiu CH, Huang JC, Yang JR, Lian WX, Lai CH, Chen YP \& Lin JH 2000 Ginseng flowers stimulate progesterone production from bovine luteal cells. American Journal of Chinese Medicine 28 371-377. (https://doi.org/10.1142/ S0192415X0000043X)

Yevshin I, Sharipov R, Kolmykov S, Kondrakhin Y \& Kolpakov F 2019 GTRD: a database on gene transcription regulation-2019 update. Nucleic Acids Research 47 D100-D105. (https://doi.org/10.1093/nar/ gky1128)

Yi T, Tan K, Cho SG, Wang Y, Luo J, Zhang W, Li D \& Liu M 2010 Regulation of embryonic kidney branching morphogenesis and glomerular development by KISS1 receptor (Gpr54) through NFAT2- and Sp1-mediated Bmp7 expression. Journal of Biological Chemistry 285 17811-17820. (https://doi.org/10.1074/jbc.M110.130740)

Received 11 June 2020

First decision 8 July 2020

Revised Manuscript received 24 August 2020

Accepted 3 September 2020 